\title{
Study on High Efficiency Milling of Steam Turbine Blade
}

\author{
Xin Yuan ${ }^{1 *}$, Takanori Yazawa ${ }^{1}$, Nobutoshi Baba ${ }^{2}$ Yukio Maeda $^{3}$, Yasuhiko Ougiya ${ }^{1}$, Tatsuhiro Kojima ${ }^{1}$
}

${ }^{1}$ Nagasaki University,

Graduate School of Engineering,

Nagasaki, Japan

E-mail:enyuanxin@yahoo.co.jp

${ }^{2}$ Nagasaki University, (Now in NIPPON SHARYO, LTD.),

Abstract-In response to global environmental issues, higher efficiency and improved operational reliability are increasingly being requested for steam turbines, essential equipment for thermal power generation. Its material is stainless steel, which is difficult to cut because of high work-hardening trend and high resistance to heat. As its complex shape and high accuracy requirement, conventional methods such as using a ball end mill have obstacles of achieve a high accuracy coexist with high efficiency. The main objectives of this study are to propose a new method called Linear Interpolation Milling(LIM) using a taper end mill and verify its validity both in theory and practice.

Keywords - Turbine blade; SUS403; High efficiency; LIM

\section{Introduction}

Removing $\mathrm{CO}_{2}$ emissions from electricity generation is a key challenge that must be overcome if the rise in global temperatures is to be limited to 2 degrees Celsius[1]. By far ultra super critical unit is the most extensive and efficient power generation technology to treat it. The requirements of its crucial component rotor blade also become higher.

The rotor blade, which is typically 60 inches in length, has a complex shape and needs to be made out by a material of low thermal conductivity to withstand temperatures above 600 degree Celsius. $12 \% \mathrm{Cr}$ steel is a series of heat-resistant steel used as turbine blade material because of its high creep rupture properties as well as superior oxidation and corrosion resistance properties[2-3]. In this experiment, the material is SUS403 martensitic stainless steel.The surface roughness should be less than $6 \mu \mathrm{m}$. So, a small diameter ball end mill and a machine tool over 4 control axes are used in the conventional machining. To satisfy the requirements of surface roughness, it is necessary to lower the pick feed, which leads to an increase of cutting distance and time. In a

\author{
Nagasaki, Japan \\ ${ }^{3}$ Toyama Prefectural University, \\ Intelligent Stems Design Engineering, \\ Toyama, Japan
}

material which is low thermal conductivity, as heat flow is hardly to diffuse, the tool wear easily progresses. As a result, it leads to deterioration of surface roughness in spite of long cutting time[4].

Work to date has shown that little work has been carried on the high efficiency milling of steam turbine blade systematically. In this study, a new method is proposed aiming at obtaining the desired surface roughness in a short cutting time and verify its validity.

\section{Proposal of LIM}

Conventional method that using ball end mill to machine turbine blade as shown in Fig.1, tool and the worktable keep an inclination angle which can be adjusted when milling. In pick feed direction, surface roughness occurs in the certainty. As the surface roughness requirement is several microns, it has to lower pick feed rate, because of this, the cutting distance will become longer and and the cutting time also increasing, generally, hand finish is also necessary.

Fig. 2 shows LIM method. In order to avoid the defect of ball end mil, cutting edge direction is parallel to pick feed direction. Instead of continuous curves, it is combined by incontinuous short straight lines which length is determined by cutting edge length. Tool and worktable keep an inclination angle so as to prevent and avoid interference between tool and workpiece. Because of machined surface approximates to plane, the ideal surface roughness value is very small. This method can choose a larger pick feed than BEM to shorten cutting distance. When real milling, it can retard tool wear and shorten machining time.

\section{Basic examination of LIM}

\section{A. Selection of pick feed}


It is necessary to select the pick feed before doing the basic examination of LIM. In pick feed direction, when minimum curvature radius of blade is denoted by $R$, and pick feed is denoted by $p f$, maximum surface waveness deviation is expressed by the formula as the following.

$$
D z=R-\sqrt{R^{2}-\left(\frac{p f}{2}\right)^{2}}
$$

Computed results are given in Fig.3. As the curvature radius of turbine blade is very large, here it will the value of $D z$ is still less than the demand value, when $p f=4 \mathrm{~mm}$, the cutting distance becomes short, so the cutting time also can be shorten. therefore, in the study, select $p f=4 \mathrm{~mm}$ to carry out the basic examination.

\section{B. Influence of feed per tooth on surface roughness}

According to the conclusion of III-A, material property and continuity of straight line, choose the coated $M$ kind cemented carbine chip which cutting edge length is $6.35 \mathrm{~mm}$. Verify the influence of feed per tooth on surface roughness within the recommended conditions. Because rotation axis is inclined relative to the workpiece normal, the maximum surface roughness is $R z=f z^{2} /\left(8 R^{\prime}\right)$ when view the cutting face in the vertical direction of rotation axis. Therefore, the theory maximum surface roughness is given as the following formula when view it in vertical direction of XY plane,

$$
R z=f z^{2} \cdot \sin \theta /\left(8 R^{\prime}\right)
$$

where $f z$ is feed per tooth, $R$ is the distance from rotation axis to cutting edge.

Computed results as given in Fig.4, within the recommended range of feed per tooth, it all can satisfy the surface roughness requirement, when $\mathrm{R}$ is not less than $12 \mathrm{~mm}$, surface roughness remains below the demand value, as a result, select $R$ above $12 \mathrm{~mm}$ to do the following experiments.

\section{Experimental method and conditions}

Experimental method is shown in Fig.5, The workpiece is cubic and it is tilted 10 degree via inclination table. Feed speed direction and pick feed direction as the figure shown. Experimental conditions is given in Table 1.

\section{Experimental result and discussion}

The influence on surface roughness of feed per tooth, cutting speed, and axial depth is shown in Fig.6. In the experiment, $f_{z}=0.38 \mathrm{~mm} /$ tooth, $V=160 \mathrm{~m} / \mathrm{min}$ and $a_{a}=0.15 \mathrm{~mm}$ is the optimal cutting condition. Besides, the cutting efficiency $Z$ is $365 \mathrm{~mm}^{3} / \mathrm{min}$, when the efficiency and one of the factor are constant, the other two factors were changed, the influences on surface roughness were examined. The results as shown in Fig.7. Surface roughness values changes within $0.9 \sim 1.2 \mu \mathrm{m}$, far less than the demand value. The cutting condition when surface roughness is 1.2 micron was chosen to verify the validity of LIM.

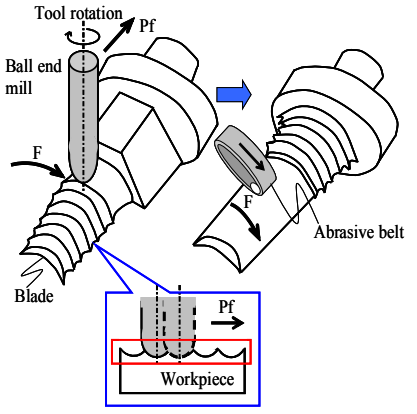

Fig.1 Conventional method

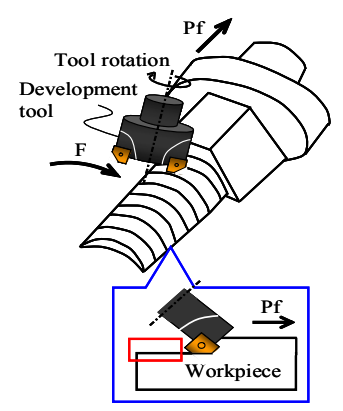

Fig.2 Proposal method

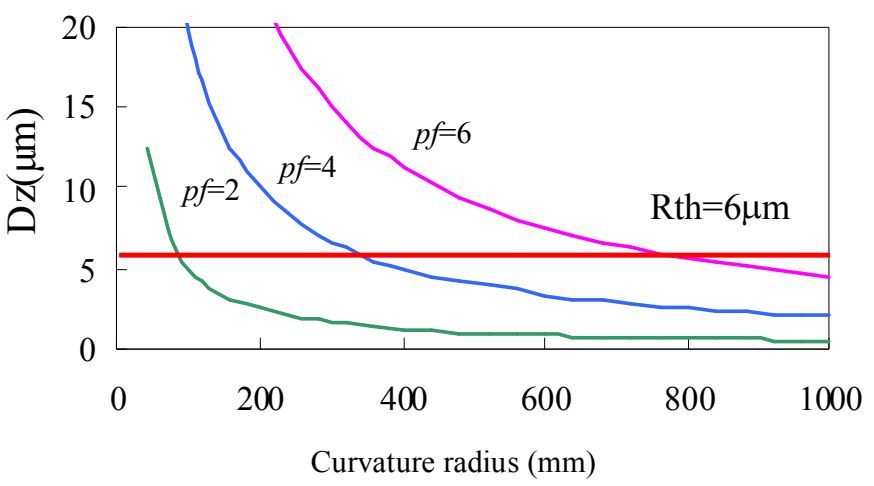

Fig.3 Relationships between curvature radius and radial deviation

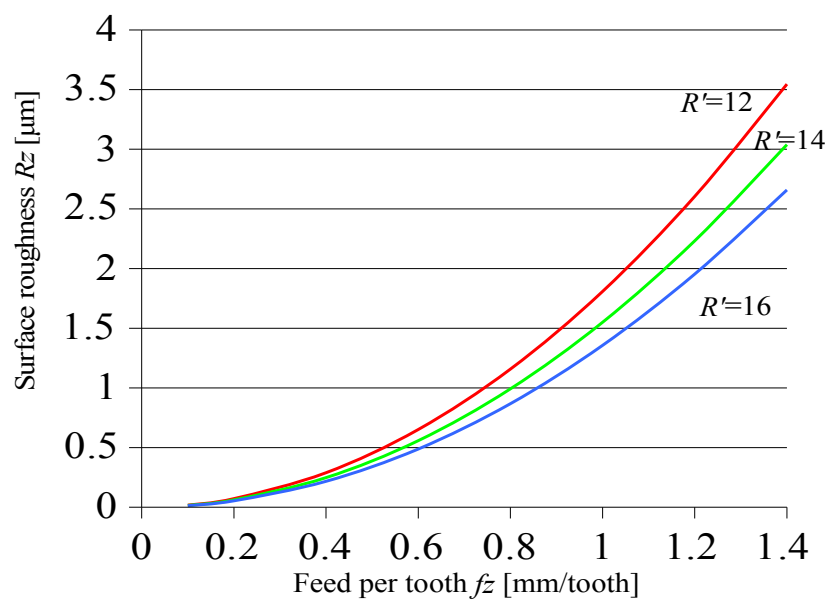

Fig.4 Influences of feed per tooth on surface roughness 


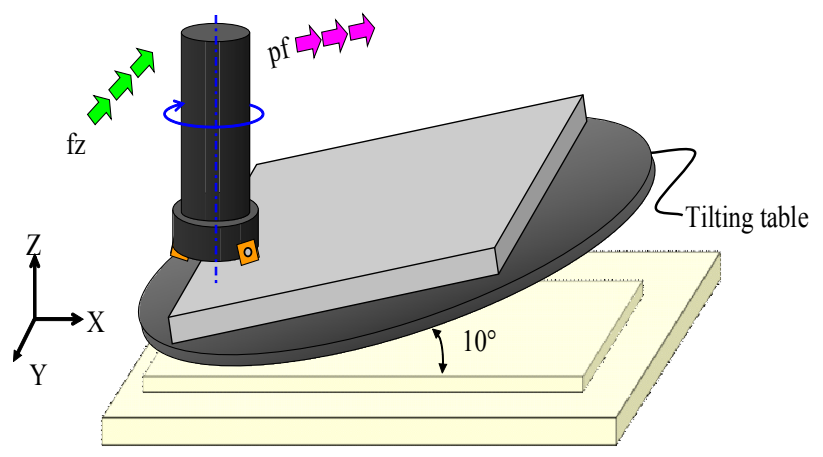

Fig.5 Experimental setup

\section{E. Evaluation of LIM}

Based on the cutting conditions and surface roughness that obtained in III-D, predict the cutting time and cutting distance of 60 inches blade.

Comparing LIM with ball end mill which radius is $3 \mathrm{~mm}$ and its material is coated cemented carbide when desired surface roughness are $1.2 \mu \mathrm{m}$ and $6 \mu \mathrm{m}$, its cutting conditions are chosen according to recommendation. The results as shown in Fig.8, it exhibits that LIM can shorten the cutting time and cutting distance than conventional method more remarkably.

\section{Conclusion}

(1) For high efficiency milling of steam turbine blade, proposed a new method LIM.

(2) Important evaluation indicators such as surface roughness, cutting time and tool wear were tested. Within this model, it exhibited that LIM was available.

\section{References}

[1] New IEA book addresses the role of electricity in meeting climate change goals, at home page $<$ http://www.iea.org/press/pressdetail.asp?PRESS_REL_ID $=4$ $14>, 2011$.

[2] H. Shao, L. Liu, H.L. Qu, Machinability study on $3 \% \mathrm{Co}-12 \% \mathrm{Cr}$ stainless steel in milling, Wear2007; 263:736-744.

[3] N.R. Dhar, M. Kamruzzaman, Cutting temperature, tool wear, surface roughness and dimensional deviation in turning AISI-4037 steel under cryogenic condition, International Journal of Machine Tools \& Manufacture 2007; 47:754-759.
[4] Nobutoshi Baba, Research on high precision and high efficient machining of complicated shape, Master's thesis, 2011(in Japanese ).

Table 1 Cutting conditions

\begin{tabular}{c|c}
\hline Machine & $\begin{array}{c}\text { Osakakiko rakuraku-mill 3V } \\
\text { Tudacoma TT-200 }\end{array}$ \\
\hline Tool & $\phi 32$ (Sandvik R210-032A25-09M) \\
\hline Workpiece $(W \times L)$ & SUS403(4×80) \\
\hline Cutting speed $\boldsymbol{V}[\mathrm{m} / \mathrm{min}]$ & $30 \sim 160$ \\
\hline Tool revolution $\boldsymbol{N}[\mathrm{rev} / \mathrm{min}]$ & $300 \sim 1600$ \\
\hline Feed per tooth $\boldsymbol{f}[\mathrm{mm} / \mathrm{tooth}]$ & $0.1 \sim 1.54$ \\
\hline Pick feed $\boldsymbol{p} \boldsymbol{f}[\mathrm{mm}]$ & 4 \\
\hline Feed speed $\boldsymbol{F}[\mathrm{mm} / \mathrm{min}]$ & $100 \sim 1200$ \\
\hline Axial depth of cut $\boldsymbol{a}_{a}[\mathrm{~mm}]$ & $0.05 \sim 0.4$ \\
\hline Coolant & Oil \\
\hline
\end{tabular}
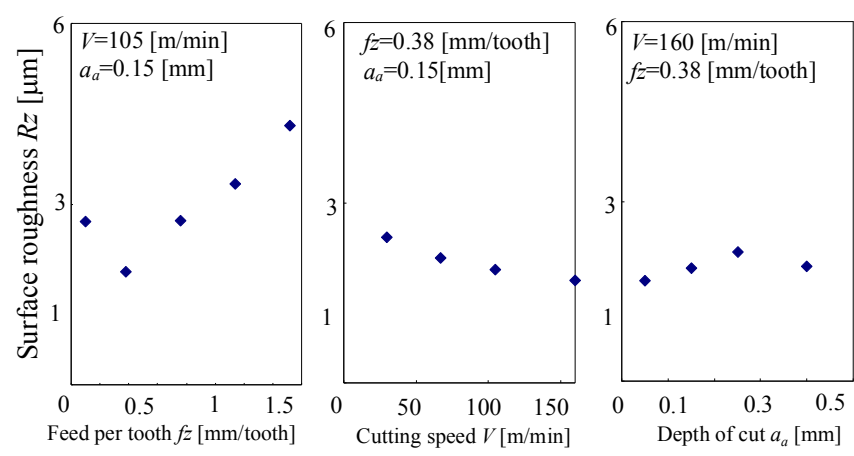

Fig.6 Influences of cutting factors on surface roughness
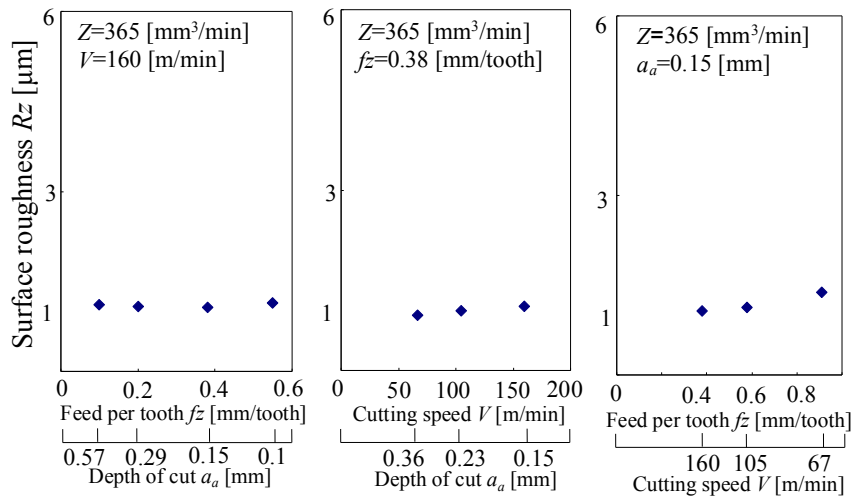

Fig.7 Influences on surface roughness as efficiency is constant

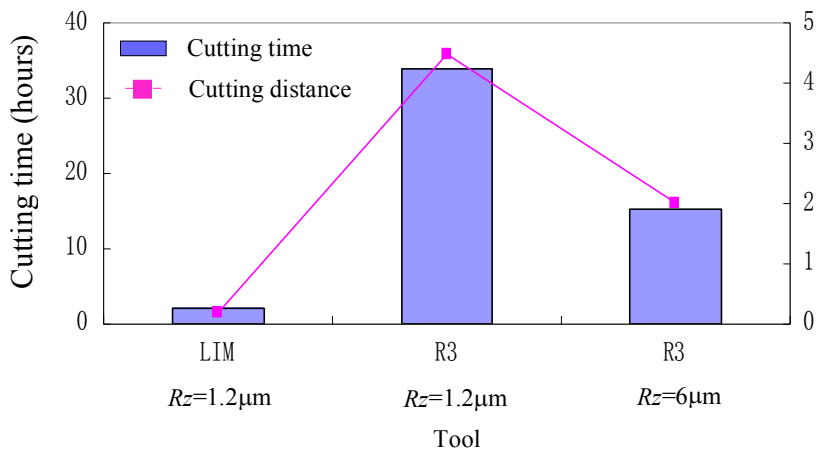

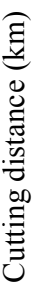

